\title{
Histidine-Rich Cationic Cell-Penetrating Peptides for Plasmid DNA and siRNA Delivery
}

\author{
Antoine Kichler, A. James Mason, Arnaud Marquette, and \\ Burkhard Bechinger
}

\section{Abstract}

Amphipathic, $\mathrm{pH}$-responsive, membrane-active peptides such as LAH4 and derivatives thereof have the 7 ability to effectively deliver genes and small interfering RNA (siRNA) into mammalian cells. Their ability to 8 bind and protect nucleic acids and then disrupt membranes when activated at low $\mathrm{pH}$ enables them to 9 harness the endocytic machinery to deliver cargo efficiently and with low associated toxicity. This chapter 10 describes protocols for the chemical synthesis of transfection peptides of the LAH4 family, complex 11 formation with nucleic acids, and their use for the in vitro delivery of either plasmid DNA or siRNA into 12 mammalian cell lines.

Keywords Gene therapy, Nonviral delivery system, Cationic amphipathic peptides, Plasmid DNA, 14 siRNA, RNA interference, Endosomal release, Histidine, Cell-penetrating peptide

A large number of monocationic and polycationic compounds have 17 been developed in recent years with the aim of overcoming the 18 bottlenecks for the development of nonviral nucleic acid-based 19 therapeutics and/or laboratory toolkits. Ideally, these compounds 20 should be multifunctional; in particular they should stabilize the 21 nucleic acid and protect it from the desired intracellular compart- 22 ment (Fig. 1). In the case of plasmid DNA, nuclear delivery is 23 required but for small interfering RNAs (siRNAs), which are used 24 for inducing RNA interference (RNAi) [1], delivery to the cytosol 25 is sufficient. In both cases, complexes are commonly taken up 26 through nonspecific endocytosis [2] and it is the ability to escape 27 from endosomes that often determines the success of a cationic 28 formulation.

One way that has been found to increase the efficiency of 30 endosomal escape of the nucleic acids consists in using the "proton 31 


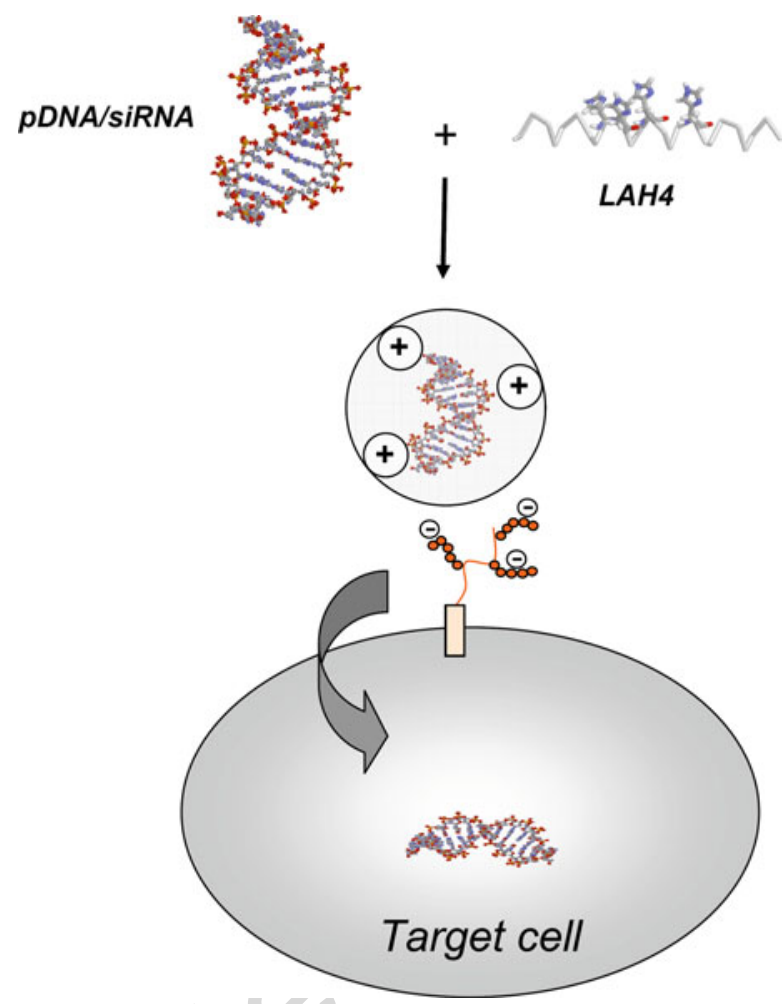

Fig. 1 Schematic representation of LAH4-mediated transfection of eukaryotic cells. Addition of an excess of LAH4 to plasmid DNA or siRNA generates complexes which exhibit a small excess of positive charges on their surface. Particles interact with the cell membrane, preferentially with proteoglycans, via nonspecific ionic interactions. The LAH4/nucleic acid complexes enter the cell through endocytosis. During acidification of the endosome, histidine residues become protonated and LAH4 interacts with the endosomal membranes in an in-plane alignment. Membrane destabilization occurs, followed by the release of DNA/siRNA into the cytosol

sponge" mechanism. This process involves a transporter-induced swelling of the endosomal compartment during acidification which leads to disruption of the endosomal membrane [3-6]. Various compounds have been described that react to the change in $\mathrm{pH}$ encountered in the endosomes [7]. Many of these compounds incorporate the imidazole group found in histidine [8-10] which has a $\mathrm{pKa}$ around 6.1. At increasingly acidic $\mathrm{pH}$ such groups are protonated leading to enhanced cationicity of the polyplexes and, potentially, some release of the vector compound and hence such groups may constitute effective triggers for nucleic acid delivering activities.

Our efforts have focused on the development of 43 pH-responsive, cationic amphipathic peptides [11-16]. These pep- 44 tides have both nucleic acid binding and membrane disruptive 45 


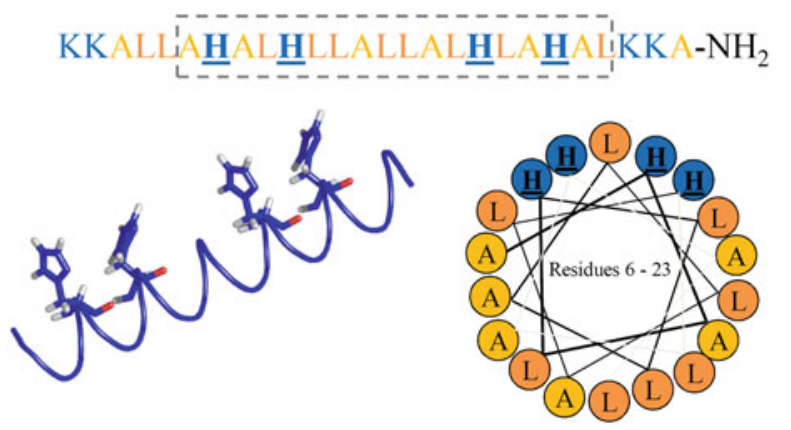

Fig. 2 Helical wheel diagram for LAH4-L1 (residues 6-23). The primary sequence (top) and three-dimensional model (left) of LAH4-L1 indicate the positions of the histidine residues and how these are located in the amphipathic helix conformation that the peptide adopts when bound either to DNA or target membranes. The helical wheel projection (right) allows one to visualize the distribution of hydrophobic and polar residues with respect to the helical axis. The angle of the positively charged helix face (histidine residues are in bold and underlined), at $\mathrm{pH} 5$, for the $\mathrm{LAH} 4-\mathrm{L} 1$ peptide is $80^{\circ}$

capabilities with their amphipathic $\alpha$-helix motif being inspired by 46 antimicrobial peptides whose main mode of action involves mem- 47 brane destabilization [17, 18]. The concept uses histidine $\mathrm{pH} 48$ triggers to release membrane-destabilizing peptides from the pep- 49 tide-nucleic acid complex (or other cargo) allowing them to inter- 50 act to and to lyse endosomal membranes. The original sequence, 51 LAH4 (KKALLALALHHLAHLALHLALA LKKA) [11], and later 52 variants, including LAH4-Ll (KKALLAHALHLLALLALHLA- 53 HALKKA) $[14,15]$, have been designed to adopt an $\alpha$-helix con- 54 formation when bound to nucleic acids [16] and, particularly, lipid 55 bilayers [19] (Fig. 2). The LAH peptides exhibit a hydrophobic 56 surface, comprising a mixture of alanine and leucine residues, and a 57 hydrophilic surface in which the four (or more) histidine residues 58 are located. The segregation of the two types of surfaces and the 59 positioning of the histidine residues (Fig. 2) are crucial to the 60 effective disordering of the membranes and the efficacy of delivery 61 mediated by the peptide $[11,15]$. The membrane disordering and 62 disruption are the final elements in a strategy that has proven to be 63 remarkably effective, with both DNA and siRNA delivery that 64 matches and often outperforms commercially available cationic 65 nonviral vectors $[11,13]$. Furthermore, we have observed only 66 low cytotoxicity associated with the $\mathrm{pH}$-responsive peptide delivery 67 system.

Notably, the LAH4 peptides have also been shown highly 69 efficient for delivering a variety of other cargoes into mammalian 70 cells including $\mathrm{CpG}$ oligonucleotides [20], proteins [20, 21], 71 adeno-associated viruses [22], lentiviruses [23-25], and quantum 72 dots [26]. 
t.1 Table 1

Sequence of some of the most efficient LAH/Dap derivatives

\begin{tabular}{|c|c|c|c|c|c|}
\hline Peptide & Sequence $^{a}$ & DNA & SiRNA & Protein & Ref. \\
\hline LAH4 & KKALLALALHHLAHLALHLALALKKA & yes & yes & yes & {$[11,13]$} \\
\hline LAH4-Ll & KKALLAHALHLLALLALHLAHALKKA & yes & yes & nd & {$[13,15]$} \\
\hline LAH6-Ll-80 & KKHLLAHALHLLALLALHLAHALAHLKKA & yes & nd & nd & [14] \\
\hline $\mathrm{LADap}(\mathrm{Me}) 6-\mathrm{Ll}$ & KKXLLAXLLXLLALLALXLLXALKXK & yes & yes & nd & {$[27]$} \\
\hline
\end{tabular}

t.7 $\quad{ }^{\mathrm{a}} \mathrm{pH}$ responsive residues are marked in bold. $X$ monomethylated 2,3-diaminopropionic acid (Dap), nd not done

It is also worth mentioning that not only histidine residues are 74 able to confer endosomolytic properties to LAH peptides. Indeed, 75 we found that the $\mathrm{pKa}$ of the $\beta$ - $\mathrm{NH} 2$ in 2,3-diaminopropionic acid 76 (Dap) is sufficiently lowered, when Dap is incorporated into pep- 77 tides, and that its protonation state is sensitive to the $\mathrm{pH}$ changes 78 that occur during endosomal acidification [12]. Integration of 79 monomethylated Dap allowed to further improve the efficiency of 80 these modified peptides [27]. Peptide analogs of LAH4 peptides 81 that are based on oligoureas have also been shown highly effective 82 in DNA transfection [8]. A short list of some of the most efficient 83 LAH/Dap peptides that we have developed in the last years are 84 shown in Table 1.

We believe that our peptide-based system has a number of advantages that makes it attractive to researchers who rely on effective delivery of nucleic acid (or other) cargoes with few side effects and, accordingly, we are pleased to provide detailed protocols for the production, characterization, and use of this emerging delivery system.

\section{Materials}

2.1 Peptide Synthesis
The peptide LAH4 (MW 2777) with the sequence KKALLALALHHLAHLALHLALALKKA- $\mathrm{NH}_{2}[11]$ or derivatives such as LAH4-L1 [15] can be purchased from a number of peptide synthesis services (e.g., ProteoGenix, Schiltigheim, France; GeneCust, Luxembourg; and many others). We would recommend requesting a custom synthesis and purchasing the peptide as desalted grade as the most cost-effective solution. Alternatively, it can be synthesized and prepared in any laboratory that has access to a solid-phase peptide synthesizer (e.g., ABI433 automatic peptide synthesizers, Weiterstadt, Germany) or the expertise and setup to go through the synthetic cycles manually.

Materials needed for peptide synthesis: 
1. Automatic peptide synthesizer (e.g., ABI433, Weiterstadt, 105 Germany).

2. Access to preparative reverse-phase HPLC instrumentation and 107 MALDI mass spectrometric analysis. HPLC is performed for 108 example on a $300 \AA$ Prontosil column (Bischoff, Leonberg, 109 Germany) of $20 \mathrm{mM}$ diameter and $250 \mathrm{mM}$ length (or similar). 110 We have purified LAH4 peptides also on columns of dimension 111 $7.8 \times 100 \mathrm{mM}$ and the conditions change accordingly. Fur- 112 thermore, during the acetonitrile shortage during the eco- 113 nomic crisis in 2008 it has proven advantageous that 114 methanol can be used instead of acetonitrile. 115

3. Solvents and Fmoc-protected amino acids (Fmoc-Ala-OH, 116 Fmoc-Leu-OH, Fmoc-Lys(Boc)-OH, and Fmoc-His(Trt)- 117 $\mathrm{OH}$, for example, from Novabiochem Merck Darmstadt, Ger- 118 many; Bachem, Heidelberg, Germany; or Applied Biosystems, 119 Weiterstadt, Germany) according to the instructions given for 120 your automatic peptide synthesizer, including HBTU 121 (2-(1H-benzo-triazole-1-yl)- 1,1,3,3-tetra-methyluronium- 122 hexafluorophosphate, Novabiochem, Merck, Darmstadt, Ger- 123 many), Dipea ( $N$-ethyldiisopropylamine, Sigma, St. Louis, 124 MO, USA), TentaGel R RAM, or TentaGel S RAM resin 125 (load $0.18-0.25 \mathrm{mmol} / \mathrm{g}$; Rapp Polymer, Tübingen, 126 Germany).

4. $5 \% \mathrm{H}_{2} \mathrm{O}, 1 \%$ triethylsilane $(97 \%$, Sigma), in trifluoroacetic acid 128 (TFA) (99.9\% Carl Roth, Karlsruhe, Germany) for the cleavage 129 reaction.

5. Diethyl ether (stabilized with BHT for analysis, SDS (Solvants 131 Documentation Syntheses), Peypin, France).

6. HPLC-grade acetonitrile, water, and TFA. When using metha- 133 nol as an alternative to acetonitrile make sure that the impu- 134 rities do not absorb at $214 \mathrm{~nm}$, thereby interfering with the 135 detection of chromatogram.

If the peptide is prepared by automated peptide synthesis it is 137 recommended to follow the detailed protocols that are provided by 138 the manufacturers of such instrumentation for the setup of the 139 synthetic cycles, including the solvents, resins, and Fmoc-protected 140 amino acid residues. Furthermore access to preparative and analyti- 141 cal reverse-phase (C4, C8, or C18) HPLC and mass spectrometric 142 characterization of the final product are necessary. As solid-phase 143 peptide synthesis is an elaborate science, which fills many textbooks 144 and libraries, discussing the details and pitfalls of the technique is 145 beyond the scope of this paper. Nevertheless, in Note $\mathbf{l}$ a short 146 outline of the fundamental idea is provided. So far the LAH4 147 peptides and their derivatives could be obtained in good yields 148 (several $100 \mathrm{mg}$ of crude product) using standard synthesis cycles 149 of automated peptide synthesizers. In our hands the crude product 150 


\subsection{Gel Mobility Shift Assay}

contains about $90 \%$ of the LAH4 sequence and can be used after desalting for preliminary transfection assays without apparent loss in efficiency when compared to the purified product. However, it should be noted that even a $99 \%$ yield of each individual cycle results in truncation products, where one residue is missing and an overall yield of the full sequence reduces to about $80 \%\left(0.99^{25}\right)$. Therefore, the shorter sequences can be separated from the desired product using preparative HPLC and identified by MALDI mass spectrometric analysis.

1. Agarose (ultrapure agarose from Invitrogen, Cergy Pontoise, 161 France).

2. TBE buffer: $89 \mathrm{mM}$ Tris- $\mathrm{HCl}, 89 \mathrm{mM}$ boric acid, $2 \mathrm{mM} 163$ EDTA, pH 8.0.

3. Loading buffer $6 \times$ : $0.25 \%$ bromophenol blue, $0.25 \%$ xylene 165 cyanol, and $30 \%$ glycerol in water.

4. SYBRSafe DNA gel stain (Invitrogen, Cergy Pontoise, France). 167

5. Electrophoresis unit. 168 169

1. pCMV-Luc is an expression plasmid encoding the firefly lucif- 170 erase gene under the control of the human cytomegalovirus 171 (CMV) immediate-early promoter. Plasmid DNA is resus- 172 pended in sterile water at $1 \mathrm{mg} / \mathrm{mL}$ and is stored at $-20^{\circ} \mathrm{C} . \quad 173$

2. The siRNA-Luc (from Sigma-Aldrich, Saint-Quentin Fallavier, 174 France) sequence that we use for knock down of luciferase has 175 been previously published [1]: sense oligonucleotide: 5- 176 '-CGUACGCGGAAUACUUCGATT-3'; antisense oligonu- 177 cleotide: 5'-UCGAAGUAUUCCGCGUACGTT-3'. Aliquots 178 of a $10 \mu \mathrm{M}$ stock solution are stored at $-20^{\circ} \mathrm{C}$.

3. The sequence of the siRNA-eGFP (Sigma-Aldrich, Saint- 180 Quentin Fallavier, France) that we use as control siRNA has 181 been published previously by Caplen et al. [28]: sense oligonu- 182 cleotide: 5'-GCAAGCUGACCCUGAAGUUCAU-3'; anti- 183 sense oligonucleotide: 5'-GAACUUCAGGGUCAGCUUGC 184 CG-3'. Aliquots of a $10 \mu \mathrm{M}$ stock solution are stored at 185 $-20{ }^{\circ} \mathrm{C}$.

4. Limit the freeze-thaw cycles of each tube. To this end, make 187 small aliquots of DNA and siRNA.

1. Dynamic light scattering (DLS) measurement system. We have 190 chosen the Zetasizer Nano-S instrument (Malvern Instru- 191 ments, UK) since it has the ability to measure molecular sys- 192 tems, from some hundreds of Daltons to micrometer-size 193 aggregates. (a)

\subsection{Dynamic Light} Scattering 
2.5 Cell Culture

2.6 Luciferase Assay

2.7 Protein Assay

2.8 MTT Cell Viability Assay

\subsection{Flow Cytometry}

2. Low-volume cuvettes. High-quality quartz cuvettes are the 195 best for the purpose of the described measurements since 196 they minimize the light scattered at the air-and liquid-win- 197 dow interfaces (Hellma, Germany). 198

3. Suspension of $60 \mathrm{~nm}$ latex nanospheres (Duke Scientific) for 199 calibration of the DLS instrument. 200

1. 24-well culture plates (from Costar). 201

2. DMEM supplemented with 100 units $/ \mathrm{mL}$ penicillin and 203 $100 \mu \mathrm{g} / \mathrm{mL}$ streptomycin. 204

3. Sterile $(0.2 \mu \mathrm{M}$ filtered $) 150 \mathrm{mM} \mathrm{NaCl}$ solution. 205 206

1. Lysis buffer: $25 \mathrm{mM}$ Tris-phosphate, $8 \mathrm{mM} \mathrm{MgCl}_{2}, 1 \mathrm{mM} 207$ AU2 dithiothreitol, $1 \mathrm{mM}$ EDTA, 15\% glycerol, 1\% Triton X-100, 208 pH 7.8.

2. Assay buffer: $25 \mathrm{mM}$ Tris-phosphate, $8 \mathrm{mM} \mathrm{MgCl}, 1 \mathrm{mM} 210$ dithiothreitol, $1 \mathrm{mM}$ EDTA, 15\% glycerol, and $2 \mathrm{mM}$ of 211 ATP - the latter component of the buffer has to be added just 212 before performing the luciferase assay (store aliquots of $1 \mathrm{~mL} 213$ of ATP at $40 \mathrm{mM}$ in water at $-20{ }^{\circ} \mathrm{C}$ ). 214

3. Make aliquots of $50 \mathrm{~mL}$ of the lysis and assay buffer and store 215 them at $-20{ }^{\circ} \mathrm{C}$. 216

4. D-Luciferin sodium salt (Invitrogen, Cergy Pontoise, France): 217 $167 \mu \mathrm{M}$ in water. Make aliquots of $10 \mathrm{~mL}$, protect the tubes 218 from light, and store them at $-20{ }^{\circ} \mathrm{C}$. 219

5. Luminometer (e.g., Victor ${ }^{2}$, PerkinElmer, Courtaboeuf, 220 France).

1. Detergent-compatible protein determination kit (e.g., the 223 Bradford protein assay from Bio-Rad, Marnes-la-Coquette, 224 France).

2. Transparent 96-well plate. 226

3. A 96-well plate spectrophotometer able to read at $595 \mathrm{~nm} . \quad 227$

1. 3-(4,5-Dimethylthiazol-2-yl)-2,5-diphenyl-tetrazolium bro- 229 mide (MTT; from Sigma) at $5 \mathrm{mg} / \mathrm{mL}$ in PBS (GIBCO). 230

2. A 96-well plate reader capable of measuring optical absorbance 231 at $\lambda=570 \mathrm{~nm}$.

1. Fluorescent FITC-siRNA-Luc: A fluorescein group is coupled 234 to the 3 end of the antisense strand of the duplex (such a 235 modification can be made by suppliers as for example Sigma). 236

2. Phosphate-buffered saline (PBS). 237 
3. Flow cytometer (e.g., FACSCalibur from Becton Dickinson, 238

Le Pont-De-Claix, France).

3.1 Peptide Synthesis
3.2 Gel Mobility Shift Assay
1. We have prepared LAH4 and related peptides by solid-phase peptide synthesis on either Millipore 9050 or ABI433 automatic peptide synthesizers using Fmoc (9-fluorenylmethyloxycarbonyl) chemistry which has also allowed us to introduce amino acid residues labeled with stable isotopes for NMR structural studies, amino acid replacements, or the addition of optical dyes $[19,29]$. As the detailed protocols and the solvents used depend on the synthesizer they shall not be specified here in detail but reference is made to the corresponding user manuals. In short, LAH4 is typically prepared following the standard protocols of the automatic synthesizer using a fourfold excess of Fmoc-protected amino acids during chain elongation with activation by HBTU and Dipea using for example a TentaGel R RAM or a TentaGel S RAM resin $(0.18-0.25 \mathrm{mmol} / \mathrm{g})$. The typical scale of the synthesis is $0.25 \mathrm{mmol}$. After cleavage of the peptide product by exposing the resin to TFA and in the presence of scavengers such as triethylsilane the crude product (several $100 \mathrm{mg}$ ) is precipitated in ice-cold diethylether and LAH4 purified by preparative HPLC using an acetonitrile/water gradient typically ranging from 5 to $60 \%$ acetonitrile in the presence of $0.1 \%$ TFA and a detection of the absorbance at $\lambda=214 \mathrm{~nm}$. The peptide typically elutes at $40 \%$ acetonitrile using for example a $\mathrm{C} 4$ reversed-phase column of $2 \mathrm{~cm}$ diameter and $25 \mathrm{~cm}$ length at a flow between 7 and $10 \mathrm{~mL} / \mathrm{min}$ (see Note 2$)$. At the end of the run the acetonitrile concentration is raised to $95 \%$ to clean the column.

2. The identity and high purity of the product should be verified by MALDI mass spectrometry and analytical HPLC.

3. After lyophilization the TFA counterions are exchanged by at least three cycles of dissolving the peptide in $5 \%$ acetate $(\mathrm{v} / \mathrm{v})$ and lyophilization (see Note 3 ).

4. Peptides are resuspended in sterile water at $1 \mathrm{mg} / \mathrm{mL}$ ( see Note $4)$.

The agarose gel mobility shift assay is a method to determine the capacity of a given compound to complex nucleic acids. More precisely, it allows one to determine the minimal amount of compound required to retard the migration of plasmid DNA or siRNA during agarose gel electrophoresis. Indeed, the complexation leads
242 243 244 245 246 247 248 249 250 251 252 253 254 255 256 257 258 259 260 261 262 263 264 265 266 267 268

269 270 


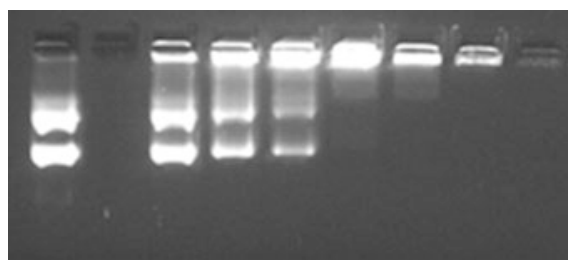

Fig. 3 Gel retardation experiment with LAH4/DNA complexes. The following conditions were used: Lanes 1-9: (1) naked DNA, (3-9) LAH4/DNA complexes with w/w ratios equal to $0.5,1,1.5,2.5,5,7.5,10$, respectively

to the formation of particles which are unable to migrate through 282 the agarose mesh $[13,16]$.

1. Prepare a $1 \%$ agarose gel ( $\geq 1.3 \%$ for siRNA) by dissolving 284 agarose in $100 \mathrm{~mL}$ of TBE buffer and boiling the suspension 285 at $100{ }^{\circ} \mathrm{C}$ using a microwave oven. After cooling down to 286 about $50{ }^{\circ} \mathrm{C}$, add $8 \mu \mathrm{L}$ of SYBRSafe to the suspension.

2. Fill the electrophoresis unit, and position a comb into the gel. 288 Using a Pasteur pipette remove bubbles from the gel and then 289 wait until agarose has solidified. Place the gel in the electro- 290 phoresis unit and remove the comb. Take care to add enough 291 TBE buffer to cover the gel.

3. Samples containing $500 \mathrm{ng}$ pDNA or $750 \mathrm{ng}$ of siRNA are 293 prepared using the same buffer conditions than those used for 294 transfection. Therefore, dilute the pDNA/siRNA in $10 \mu \mathrm{L}$ of 295 $150 \mathrm{mM} \mathrm{NaCl}$.

4. Take a tube containing a $1 \mathrm{mg} / \mathrm{mL}$ solution of LAH4 (or der- 297 ivative) from the freezer. After thawing, vortex vigorously the 298 tube - an additional short sonication using a bath sonicator 299 may be performed-before withdrawing the desired amount 300 of peptide from the tube.

5. Dilute increasing amounts of peptide in $10 \mu \mathrm{L}$ of $\mathrm{NaCl} 302$ $150 \mathrm{mM}$ (typically, use peptide-nucleic acid weight/weight 303 ratios ranging from $0.5: 1$ to $10: 1$ ).

6. Mix the nucleic acids and the peptide, and incubate for about 305 $15 \mathrm{~min}$ at room temperature.

7. Add $3 \mu \mathrm{L}$ of loading buffer to each sample, mix, and then load 307 the samples into the wells of the agarose gel. Also include a 308 sample containing nucleic acids without peptide. 309

8. Electrophoresis conditions: $100 \mathrm{~V}$ for $20-30 \mathrm{~min}$. 310

9. Visualize the agarose gel stained with SYBRSafe using an UV 311 illuminator. An example of gel is shown in Fig. 3: the results 312 indicate that addition of a cationic peptide such as LAH4 313 inhibits in a dose-dependent manner the migration of DNA 314 ( see Note 5). In this experiment, complete retardation was 315 


\subsection{Plasmid DNA}

\subsection{Dynamic Light Scattering}

\subsubsection{Preparation of LAH4 and DNA Stock Solutions}

3.4.2 Size Measurement of LAH4-DNA Complexes obtained at an LAH4/DNA w/w ratio of 2.5. This ratio of 2.5 316 corresponds to 0.59 LAH4 peptide per base pair or expressed 317 as a positive/negative charge ratio to +1.5 ( see Notes 6 and 7). 318

Plasmid DNA is purified using a commercially available kit (e.g., 321 NucleoBond from Macherey-Nagel, Hoerdt, France). The concen- 322 tration of the DNA solution is determined by spectrophotometry at 323 $\lambda=260 \mathrm{~nm}$ taking into account that one absorbance unit corre- 324 sponds to $50 \mu \mathrm{g} / \mathrm{mL}$ of double-stranded DNA. The optical density 325 is also taken at $\lambda=280 \mathrm{~nm}$ ( see Note 8). 326

The protocol described below outlines (1) the preparation of the 328 peptide (here LAH4 as an example) and the DNA stock solutions, 329 (2) the measurement of the size of the transfection complexes, and 330 (3) the critical analysis of the recorded data. 331

The procedure for preparation of LAH4 and DNA stock solutions 333 constitutes a major factor for the success of size measurement of 334 LAH4-DNA complexes and should be done step by step as 335 described below.

1. Weight the appropriate amount of peptide and prepare a $1 \mathrm{mg} / 337$ $\mathrm{mL}$ stock solution of LAH4 in the desired buffer (e.g., $10 \mathrm{mM} 338$ acetate, $\mathrm{pH} 5$ ) (see Notes $\mathbf{4}$ and $\mathbf{9}$ ). Mix by gently tapping and 339 shaking the tube. Sonication of the LAH4 solution for periods 340 of about 10-30 s will help to remove any visible aggregated 341 powder.

2. Perform a first size measurement on the LAH4 stock solution 343 by DLS (as explained in the following sections) in order to 344 confirm the solubility of the peptide at low $\mathrm{pH}$. If this is not the 345 case, ultracentrifugation of the solution at $100,000 \times g$ for $1 \mathrm{~h} 346$ has to be performed in order to remove the remaining aggre- 347 gates and impurities bigger than about $\approx 100 \mathrm{~nm}$ ( see Note 9). 348

3. Prepare a $1 \mathrm{mg} / \mathrm{mL}$ stock solution of DNA following the same 349 protocol described for LAH4 with the exception of the 350 sonication step. 351

1. Prepare a minimum of $40 \mu \mathrm{L}$ of complexes by mixing the right 353 amount of the peptide and the DNA stock solutions in an 354 Eppendorf tube. Note that the concentrations of the stock 355 solution were chosen high enough so that the complexes 356 could be detected by our experimental system.

2. Transfer the LAH4-DNA mixture in the low-volume quartz 358 cuvette. Place the cuvette in the sample holder of the DLS 359 measurement system.

3. Set the working temperature and the related physical para- 361 meters needed by the program to perform the mathematical 362 
procedure of data inversion. Refractive index of the buffer and 363 of the complexed molecules at $\lambda=633 \mathrm{~nm}$ have to be known. 364 At $25{ }^{\circ} \mathrm{C}$, the index of refraction of pure water $(n=1.33)$ and 365 of pure proteins $(n=1.45)$ can be considered as good approx- 366 imations for the solvent and the complex, respectively. Prior to 367 the measurements the geometry of the cuvette and the viscosity 368 of the buffer have also to be entered in the program. 369

4. Record a first measurement after equilibration of the sample in 370 the cuvette. Perform at least four more acquisitions to ensure 371 the reproducibility of the measurements and the stability of the 372 sample over time.

5. After measurements, the sample can be recovered for use in 374 other experiments.

3.4.3 Analyzing the Quality of the Data
A careful analysis of the results has to be performed in order to 377 avoid artifacts and to prevent misinterpretation and/or overinter- 378 pretation of the data. For this, it is useful to recall some basics of the 379 functioning of the DLS instrument and of the mathematical algo- 380 rithm applied to the data.

The software controlling the Zetasizer Nano S performs an 382 analysis of the time autocorrelation function of the scattered light 383 to extract the size distribution of the dissolved particles. The basic 384 idea behind the experiment is that the scattering of a light beam 385 depends on the size of the particles in solution and consequently 386 their velocity. If the particles are small, they diffuse fast and the 387 "memory" is only short lived. In other words the correlation in the 388 diffraction properties between two intervals separated by a given 389 period of time is low. If a particle is large, it diffuses slowly and the 390 correlation remains even if the separating time period is extended. 391 According to the general theory, the intensity of the autocorrela- 392 tion function is proportional to the square of the electric field-field 393 time autocorrelation function, denoted as $g^{(I)}(t)$. The latter takes 394 complex forms depending on the size, shape, and composition of 395 the scattering particles.

The averaged intensity hydrodynamic radius $\left\langle R_{\mathrm{H}}\right\rangle$ and the 397 polydispersity index (PDI) values (an estimate of the distribution 398 width around $\left\langle R_{\mathrm{H}}>\right.$ ) are calculated from a mathematical analysis 399 implemented into the Malvern software. For this, the correlation 400 functions are compared to a monoexponential decay $g^{(I)}(t)=\exp 401$ $(-G t)$, supposing a monodisperse population of spherical particles. 402 In this case, the particle's hydrodynamic radius is proportional to 403 the invert of the time relaxation of the decay. The decay rate is equal 404 to $G=D q^{2}$, where $D$ is the diffusion coefficient of the particles and 405 $q$ the magnitude of the scattering wave vector that depends on $\lambda_{0}, \theta, 406$ AU3 and the refractive index of the solvent. The Stokes-Einstein rela- 407 tion, $D=k_{\mathrm{B}} T / 6 \pi \eta<R_{\mathrm{H}}>$, where $k_{\mathrm{B}}$ is Boltzmann's constant and $\eta 408$ is the dynamic viscosity, then relates the diffusion coefficient to 409 
$<R_{\mathrm{H}}>$. PDI values are calculated from the deviation of the data from the monoexponential decay. With this background in mind, 410 analyze carefully the experimental data in the following manner:

1. Compare the average intensity over time of the signal arising from the transfection complexes (known as SLS, for static light scattered) with that of a "blank measurement" recorded with the buffer only, in the same quartz cuvette. If the intensity of the latter is much higher, the molecules in the former are probably strongly aggregated involving very large size particles (up to several micrometers). In this condition special attention has to be given to the analysis of the data and to possible artifacts generated by the inversion algorithm.

2. Inspect the autocorrelation function measured on your samples. If the value at $t=0 \mu$ s is close to zero, the density of the complexes is too low to be measured. The peptide and DNA concentrations of the stock solutions have to be increased in order for the oligomers to be detected. Alternatively sedimentation of large size aggregates might have led to the depletion of the molecules in solution that cannot longer be observed by the system.

3. The PDI indicates the deviation of the sample when compared to an ideal monodispersed sample. For PDI values from 0 to 0.2 , the sample solution can be considered as monodisperse. If PDI $>0.7$, the sample is highly polydisperse and the values of the hydrodynamic radius given by the instrument are probably meaningless. Short periods of sonication of the sample may help to homogenize the solution [30].

1. The day prior to transfection, use trypsin to detach actively dividing cells from the culture flask (Corning).

2. After addition of $15 \mathrm{~mL}$ of DMEM supplemented with $10 \%$ of serum, the cells are counted.

3. Finalize the protocol of the experiment in order to determine how many wells are needed. Notably, transfection experiments are usually done using duplicates or triplicates.

4. The required volume of cell suspension to obtain a confluence 911-Luc cells, we use 200,000 cells/well) (see Note 10). Dilute the cell suspension with a volume of culture medium which allows the addition of $1 \mathrm{~mL}$ of culture medium into each well of the 24-well plate.

5. The cells are then incubated at the appropriate cell culture conditions (a humidified tissue culture incubator at $37{ }^{\circ} \mathrm{C} \quad 452$ and $\left.5 \% \mathrm{CO}_{2}\right)$. 
3.6 Cell Transfection

\subsubsection{DNA Transfection}

Before starting the DNA/siRNA transfection experiment, the cells 455 should be examined using a microscope. This observation allows 456 for verification of the confluence of the cells and also of the (good) 457 shape of the cells. The peptide-DNA or siRNA complexes are 458 generated just before transfection of the cells. For a transfection 459 performed in duplicate, the following protocols are used. $\quad 460$

1. The tube containing the plasmid DNA is thawed and gently 462 vortexed. Take $4 \mu \mathrm{g}$ of plasmid DNA (for one duplicate) and 463 dilute them in $100 \mu \mathrm{L}$ of sterile $(0.20 \mu \mathrm{M}$ filtered) 464 $150 \mathrm{mM} \mathrm{NaCl}$.

2. The tube containing a $1 \mathrm{mg} / \mathrm{mL}$ solution of LAH4 is thawed. 466 The tube is then vigorously vortexed - a short sonication using 467 a bath sonicator may be additionally performed-before with- 468 drawing the desired amount of peptide (see Notes 11 and 12). 469 Complete to $100 \mu \mathrm{L}$ with sterile $150 \mathrm{mM} \mathrm{NaCl}$.

3. Mix the DNA with the peptide, centrifuge very shortly to pull 471 down all the drops, and let the tube at room temperature for 472 about $15 \mathrm{~min}$.

4. Add to the mixture serum-free medium (if applicable) to obtain 474 a final volume of $1 \mathrm{~mL} ; 0.5 \mathrm{~mL}$ of the transfection mixture are 475 then put in each well of the duplicate.

5. Remove the culture medium from the cells by aspiration. If the 477 cells that are used adhere well, they may be rinsed with PBS in 478 order to remove all serum containing proteins from the wells 479 ( see Note 13).

6. Add $0.5 \mathrm{~mL}$ of LAH4/DNA transfection medium into each 481 well of the duplicate and incubate at $37^{\circ} \mathrm{C}$ for $2-4 \mathrm{~h}$. 482

7. Remove carefully the transfection medium and replace it with 483 $1 \mathrm{~mL}$ of complete culture medium (DMEM supplemented 484 with 100 units $/ \mathrm{mL}$ penicillin, $100 \mu \mathrm{g} / \mathrm{mL}$ streptomycin, and 485 $10 \%$ of fetal calf serum). $\quad 486$

8. Incubate at $37^{\circ} \mathrm{C}$ for $28-48 \mathrm{~h}$, depending on the cell type. 487

9. Analyze the cells for luciferase expression (see Notes 14 and 488 $15)$ and protein content or proceed for the MTT cell viability 489 assay (see below). $\quad 490$

491

3.6.2 siRNA Transfection
1. Thaw tubes containing the siRNA-Luc. Take $0.46 \mu \mathrm{g}(3.5 \mu \mathrm{L} 492$ of the $10 \mu \mathrm{M}$ siRNA solution) of siRNA-Luc (to obtain a final 493 concentration in the wells of $50 \mathrm{nM}$ ). Complete to $30 \mu \mathrm{L}$ with 494 $\mathrm{NaCl} 150 \mathrm{mM}$.

2. The tube containing a $1 \mathrm{mg} / \mathrm{mL}$ solution of LAH4 is thawed. 496 The tube is then vigorously vortexed-a short sonication step 497 using a bath sonicator may be additionally applied-before 498 
withdrawing the desired amount of peptide (see Notes 11 and 499 12). Complete to $30 \mu \mathrm{L}$ with $\mathrm{NaCl} 150 \mathrm{mM}$ (see Note 14). $\quad 500$

3. Of note, transfection complexes of related composition should 501 be prepared with a control siRNA such as a siRNA-GFP. This 502 control is important in order to ascertain that the silencing is 503 gene specific. 504

4. Mix the siRNA with the peptide, centrifuge very shortly to pull 505 down all the drops, and let the tube at room temperature for 506 about $15 \mathrm{~min}$.

5. Add to the mixture serum-free medium (if possible) to obtain a 508 final volume of $0.7 \mathrm{~mL} ; 0.350 \mathrm{~mL}$ of the transfection mixture 509 are then added to each well of the duplicate. 510

6. Remove the culture medium from the cells by aspiration. If the 511 cells that are used adhere well, the cultures may be rinsed with 512 PBS in order to remove serum containing proteins from the 513 wells. 514

7. Add $0.350 \mathrm{~mL}$ of LAH4/siRNA transfection medium into 515 each well of the duplicate and incubate at $37^{\circ} \mathrm{C}$ for $2-4 \mathrm{~h}$. $\quad 516$

8. Remove carefully the transfection medium and replace it with 517 $1 \mathrm{~mL}$ of complete culture medium (DMEM supplemented 518 with 100 units $/ \mathrm{mL}$ penicillin, $100 \mu \mathrm{g} / \mathrm{mL}$ streptomycin, and 519 $10 \%$ of fetal calf serum). 520

9. Incubate at $37^{\circ} \mathrm{C}$ for $28-48 \mathrm{~h}$, depending on the cell type. 521

10. Analyze the cells for luciferase expression and protein content 522 or proceed for the MTT cell viability assay (see below) (see 523 Notes 16 and 17). 524

3.7 Luciferase Assay To determine luciferase activity, the following protocol is used: $\quad 526$

1. Remove carefully the culture medium from the 24 -well plates. 527

2. Add $250 \mu \mathrm{L}$ of lysis buffer to each well. $\quad 528$

3. After $10 \mathrm{~min}$, the cell lysate is recovered and transferred into 529 $1.5 \mathrm{~mL}$ Eppendorf tubes 4. Centrifuge the tubes for $5 \mathrm{~min}$ at 530 $10,000 \times g$ to pellet debris. 531

4. Take $50 \mu \mathrm{L}$ of the supernatant of each tube and transfer them 532 into the wells of a white 96-well plate. 533

5. Measure the bioluminescence using a luminometer which 534 automatically injects $100 \mu \mathrm{L}$ of buffer assay and $100 \mu \mathrm{L}$ of 535 luciferin solution. $\quad 536$

6. Read luminescence over $10 \mathrm{~s}$. 537

7. Remove the luciferase background (obtained with the lysate 538 from nontransfected cells) from each value. 539

8. Calculate the light units for $10 \mathrm{~s} / 250 \mu \mathrm{L}$ of sample. 540 
9. After having measured the protein content (see below), express 541 the efficiency as light units $/ 10 \mathrm{~s} / \mathrm{mg}($ or $\mu \mathrm{g})$ of protein. $\quad 542$

3.8 Protein Content

The protein determination procedure described here is valid for the 544

Bradford protein assay from Bio-Rad (see Note 18).

1. Transfer $2 \mu \mathrm{L}$ of cell lysate to a transparent 96-well plate. Of 546 note, add a control with $2 \mu \mathrm{L}$ of lysis buffer in order to obtain 547 the background value. $\quad 548$

2. Add $200 \mu \mathrm{L}$ of Bradford reagent which was diluted five times in 549 water.

550

3. Mix gently.

551

4. Read absorbance at $\lambda=595 \mathrm{~nm}$ and determine the protein 552 content in each sample by using a bovine serum albumin stan- 553 dard curve.

3.9 MTT Cell Viability Assay

\subsection{Flow Cytometry for the Evaluation of the Delivery Efficiency of the siRNA}

This assay is used to measure the cell viability ( see Note 18). It 556 therefore allows for an evaluation of the cytotoxicity of the trans- 557 fection complexes.

1. The transfection should be performed using the same experi- 559 mental conditions as those used for the luciferase assay (DNA 560 or siRNA).

561

2. Instead of removing the medium and lysing the cells after 562 28-48 h of transfection, add to the medium MTT reagent at 563 a final concentration of $0.5 \mathrm{mg} / \mathrm{mL}$ per well. 564

3. Cells are incubated at $37{ }^{\circ} \mathrm{C}$ and $5 \% \mathrm{CO}_{2}$ for $3 \mathrm{~h}$. $\quad 565$

4. Remove the medium from the cells. 566

5. Add $500 \mu \mathrm{L}$ DMSO to each well to dissolve the formazan 567 crystals.

6. Transfer $100 \mu \mathrm{L}$ from each sample into a transparent 96-well 569 plate and measure absorption at $\lambda=570 \mathrm{~nm}$. 570

7. Untreated cells serve as control ( $=100 \%$ cell viability). 571

By using a fluorescently labeled siRNA and flow cytometry it is 573 possible to quantify the amount of nucleic acid that is associated 574 with or endocytosed by the cells.

1. Complexes are made fluorescent by using a fluorescently 576 labeled siRNA-Luc (an FITC group is conjugated to the $3^{\prime} 577$ end of the antisense strand).

2. After preparation of the complexes as described for cell trans- 579 fection, they are added to 911-Luc cells (final siRNA 580 concentration $=50 \mathrm{nM}$ ). 
3. After $3 \mathrm{~h}$ of incubation at $37^{\circ} \mathrm{C}$, cells are washed with cold PBS and harvested in $1 \mathrm{mM}$ EDTA in PBS and 10,000 cells are then analyzed by flow cytometry.

1. Solid-phase peptide synthesis is based on a cycle of repetitive (and therefore potentially automated) steps where one amino acid after the other is connected to the growing peptide chain. The synthesis starts with the most $\mathrm{C}$-terminal residue of the sequence which is attached to beads of a solid resin and progresses toward the $\mathrm{N}$-terminus (i.e., reverse to the conventional reading of polypeptide sequences). By attaching the intermediate and final products to the solid support it is possible to freely exchange the solvents simply by washing steps where the resin is retained by a ceramic filter funnel (or column) without the need of recrystallization or other types of intermediate purification.

A synthetic cycle starts with one amino acid being attached to the resin by its carboxyl group and the amine being protected (e.g., Fmoc). In a first step the protection group is cleaved from the chain which liberates the amino group for the following reaction. In parallel the amino acid $\mathrm{N}$-terminal $(n-1)$ to the one already on the resin $(n)$ is activated chemically; thus its carboxyl group reacts with the amine of the residue already coupled to the solid support. The amine group of this amino acid is protected (e.g., by a Fmoc group); thus it cannot polymerize with its like. By mixing an excess of this activated amino acid with the chain on the resin and incubation of this reaction mixture by several minutes the polypeptide chain grows by one residue, and a new cycle can start by removal of the protection group.

Ideally the reaction yield of each step is $>99 \%$, but critical steps may occur where the cleavage of the protection group or the addition of the next amino acid residues is hindered (e.g., sterically). In such cases, increased temperatures, double couplings, extended couplings, a change in chemistry and/or solvents, or the use of pseudoproline residues may be helpful (e.g., [31]) and references cited therein).

2. The optimal flow to obtain best resolution on this type of column would be about three times increased, but this is not always possible as the resulting back pressure of the HPLC system and column exceeds the capacity of the instrument.

3. More recent studies suggest that a more reliable method consists in at least three cycles of dissolving $1 \mathrm{mg} / \mathrm{mL}$ peptide in $2 \mathrm{mM} \mathrm{HCl}$ (respecting a few-fold excess over the TFA ions) 
and lyophilization [32]. If the peptide is purchased from a 627 commercial source make sure you have information about the 628 counterions. Note that the molecular weight to be considered 629 during the preparation of a solution is much different if you 630 have TFA $(2777+9 \times 113)$, acetate $(2777+9 \times 59)$, or $\mathrm{Cl}^{-} 631$ $(2777+9 \times 36)$ counterions to nine cationic sites of the 632 polypeptide sequence.

4. We recommend the storage of the peptide powder over longer 634 time periods at $-20^{\circ} \mathrm{C}$. Therefore, before usage the container 635 and the powder have to be first equilibrated thoroughly to 636 reach room temperature, which can take many minutes, even 637 hours. In order to avoid the condensation of water into the 638 peptide powder and its recipient, it is important that during 639 this process the vial remains tightly sealed. Thereafter, weight 640 the appropriate amount of peptide and resuspend LAH4 at a 641 final concentration of, e.g., stock solution of $1 \mathrm{mg} / \mathrm{mL}$. Before 642 transferring the vial with the peptide back into the cold assure 643 that it is tightly sealed with, for example, Parafilm. Avoid 644 repeated freezing and thawing of the stock solution. Prepare 645 rather small aliquots ( $500 \mu \mathrm{L}$ in $1.5 \mathrm{~mL}$ Eppendorf tubes). $\quad 646$

5. If the condensation of the nucleic acids is very efficient, then 647 the nucleic acids are no more accessible to SYBRSafe. This, in 648 turn, results in the absence of a nucleic acid stain in the agarose 649 gel. This is for example the case in Fig. 3 with the highest 650 LAH4/DNA ratio.

6. The peptide LAH4 has five positive charges at neutral $\mathrm{pH}: 652$ indeed, the C-terminus is amidated and therefore it does not 653 present a negative charge. Also of note, at acidic $\mathrm{pH}$, the 654 imidazole groups of the histidine residues become protonated 655 and this adds four positive charges to the peptide (net 656 charge $=+9$ at $\mathrm{pH} 5$ ).

7. In our hands, 2.5 to 5 times more peptide of the LAH4 family 658 is required to retard the migration of siRNAs when compared 659 with plasmid DNA. This indicates that complex formation and 660 interactions of the cationic peptides with plasmid DNA are 661 different when compared to siRNA [13].

8. The quality of plasmid DNA may influence the transfection 663 process and only siRNA and DNA of high quality should be 664 used. It is recommended that the optical density ratio OD260/ 665 $\mathrm{OD} 280$ is $\geq 1.8$.

9. For biophysical experiments we prefer to use an LAH4 stock 667 solution at low $\mathrm{pH}$, where the peptide is monomeric [30], and 668 therefore, mixes with DNA in the most homogenous manner. 669 In this manner, changing back and forth between acidic and 670 neutral $\mathrm{pH}$ gives reproducible DLS measurements for the 671 transfection complexes. 
10. It is usually recommended to transfect cells at a confluence of $50-80 \%$. However, the optimal cell density for efficient DNA or siRNA transfection may vary between cell types. In any case, it is important to keep the same seeding protocol for a given cell type between the experiments. It is also important, especially when using primary cells, to use cells having approximately the same number of passages.

11. The optimal peptide-nucleic acid ratio for transfection has to be determined for each new cell line.

12. The optimal peptide-nucleic acid ratio may be different for a given cell line for plasmid DNA and siRNA. For example, in our hands using 911 cells, the optimal weight/weight peptide-nucleic acid ratio for siRNA delivery is higher than the one for plasmid DNA transfection.

13. The DNA and siRNA transfection process with LAH4 and derivatives is reduced in the presence of serum [14]. Therefore, when possible, avoid addition of serum-or at low \%—during the $2-3$ h of incubation.

14. Optimization of each step of the transfection process should be undertaken if the DNA/siRNA transfection efficiency is low. Besides testing various peptide-nucleic acid ratios, other parameters may be changed: concentration of nucleic acids per well; duration of incubation of the complexes with the cells; buffer conditions employed during complexation (e.g., water seems to give better results with the LAH4 peptides for the delivery of siRNA [13]); confluence of the cells; percentage of serum in the medium during the $2-4 \mathrm{~h}$ of incubation. Another way to improve the transfection consists in not replacing the transfection medium after the 2 to $4 \mathrm{~h}$ incubation step. In this case, add culture medium containing serum into the wells.

15. It has been shown for PEI-DNA complexes that just after addition of the complexes to the cells, a short centrifugation step of the culture plates at $1000 \mathrm{rpm}(=138 \times g)$ for $5 \mathrm{~min}$ increases the transfection efficiency [33]. This step may also be performed in order to increase the transfection of DNA/siRNA by LAH4 and derivatives.

16. When using cells expressing a reporter gene such as luciferase for measuring the efficiency of siRNA knockdown, one has to 710 take into account the fact that the efficiency may vary from one cellular clone to another. Indeed, the number of integrated copies probably influences the level of expression and thus also 713 the efficiency of silencing. Cells expressing a reporter gene are very useful for a first evaluation of the siRNA transfection 714 efficiency of compounds. However, for further experiments, 715 the best manner to evaluate the siRNA delivery efficiency of a 
system consists in targeting endogenous genes such as 718 GAPDH.

17. For siRNA experiments, it is important to choose the amount 720 of peptide which gives the highest transfection efficiency asso- 721 ciated with the lowest cytotoxicity. Indeed, cell toxicity may 722 lead to nonspecific knockdown of genes.

18. For determination of the amount of protein, use a detergent- 724 compatible detection kit. Notably, the total cellular protein 725 content is also an indicator of cell viability.

\section{Acknowledgments}

We thank Christopher Aisenbrey for his assistance on the section 728 concerning the chemical synthesis of the peptides.

\section{References}

1. Elbashir SM, Harborth J, Lendeckel W, Yalcin A, Weber K, Tuschl T (2001) Duplexes of 21-nucleotide RNAs mediate RNA interference in cultured mammalian cells. Nature 411 (6836):494-498. https://doi.org/10.1038/ 35078107

2. Kopatz I, Remy JS, Behr JP (2004) A model for non-viral gene delivery: through syndecan adhesion molecules and powered by actin. J Gene Med 6(7):769-776. https://doi.org/ $10.1002 /$ jgm.558

3. Behr JP (1997) The proton sponge: A trick to enter cells the viruses did not exploit. Chimia 51(1-2):34-36

4. Kichler A, Leborgne C, Coeytaux E, Danos O (2001) Polyethylenimine-mediated gene delivery: a mechanistic study. J Gene Med 3 (2):135-144. https://doi.org/10.1002/jgm. 173

5. Neuberg P, Kichler A (2014) Recent developments in nucleic acid delivery with polyethylenimines. Adv Genet 88:263-288. https://doi. org/10.1016/B978-0-12-800148-6.000092

6. Sonawane ND, Szoka FC Jr, Verkman AS (2003) Chloride accumulation and swelling in endosomes enhances DNA transfer by polyamine-DNA polyplexes. J Biol Chem 278 (45):44826-44831. https://doi.org/10. 1074/jbc.M308643200

7. Gao WW, Chan JM, Farokhzad OC (2010) $\mathrm{pH}$-responsive nanoparticles for drug delivery. Mol Pharm 7(6):1913-1920. https://doi. org $/ 10.1021 / \mathrm{mpl} 100253 \mathrm{e}$
8. Douat C, Aisenbrey C, Antunes S, Decossas M, Lambert O, Bechinger B, Kichler A, Guichard G (2015) A cell-penetrating foldamer with a bioreducible linkage for intracellular delivery of DNA. Angew Chem Int Ed Engl 54 (38):11133-11137. https://doi.org/10. 1002/anie.201504884

9. Kos P, Lachelt U, Herrmann A, Mickler FM, Doblinger $\mathrm{M}$, $\mathrm{He} \mathrm{D}$, Krhac Levacic A, Morys S, Brauchle C, Wagner E (2015) Histidine-rich stabilized polyplexes for cMetdirected tumor-targeted gene transfer. Nanoscale 7(12):5350-5362. https://doi.org/10. $1039 / \mathrm{c} 4 \mathrm{nr} 06556 \mathrm{e}$

10. Midoux P, Pichon C, Yaouanc JJ, Jaffres PA (2009) Chemical vectors for gene delivery: a current review on polymers, peptides and lipids containing histidine or imidazole as nucleic acids carriers. $\mathrm{Br} \mathrm{J}$ Pharmacol 157 (2):166-178. https://doi.org/10.1111/j. 1476-5381.2009.00288.x

11. Kichler A, Leborgne C, Marz J, Danos O, Bechinger B (2003) Histidine-rich amphipathic peptide antibiotics promote efficient delivery of DNA into mammalian cells. Proc Natl Acad Sci U S A 100(4):1564-1568. https://doi.org/10.1073/pnas.0337677100

12. Lan Y, Langlet-Bertin B, Abbate V, Vermeer LS, Kong X, Sullivan KE, Leborgne C, Scherman D, Hider RC, Drake AF, Bansal SS, Kichler A, Mason AJ (2010) Incorporation of 2,3-diaminopropionic acid into linear cationic amphipathic peptides produces $\mathrm{pH}$-sensitive vectors. Chembiochem 11(9):1266-1272. https://doi.org/10.1002/cbic.201000073 
13. Langlet-Bertin B, Leborgne C, Scherman D, Bechinger B, Mason AJ, Kichler A (2010) Design and evaluation of histidine-rich amphipathic peptides for siRNA delivery. Pharm Res 27(7):1426-1436. https://doi.org/10.1007/ s1 1095-010-0138-2

14. Mason AJ, Leborgne C, Moulay G, Martinez A, Danos O, Bechinger B, Kichler A (2007) Optimising histidine rich peptides for efficient DNA delivery in the presence of serum. J Control Release 118(1):95-104. https://doi.org/10.1016/j.jconrel.2006.12. 004

15. Mason AJ, Martinez A, Glaubitz C, Danos O, Kichler A, Bechinger B (2006) The antibiotic and DNA-transfecting peptide LAH4 selectively associates with, and disorders, anionic lipids in mixed membranes. FASEB J 20 (2):320-322. https://doi.org/10.1096/fj. 05-4293fje

16. Prongidi-Fix L, Sugawara M, Bertani P, Raya J, Leborgne C, Kichler A, Bechinger B (2007) Self-promoted cellular uptake of peptide/ DNA transfection complexes. Biochemistry 46(40):11253-11262. https://doi.org/10. $1021 /$ bi700766j

17. Bechinger B, Lohner K (2006) Detergent-like actions of linear amphipathic cationic antimicrobial peptides. Biochim Biophys Acta 1758 (9):1529-1539. https://doi.org/10.1016/j. bbamem.2006.07.001

18. Bechinger B (2015) The SMART model: soft membranes adapt and respond, also transiently, in the presence of antimicrobial peptides. J Pept Sci 21(5):346-355. https://doi.org/10. $1002 /$ psc. 2729

19. Georgescu J, Munhoz VH, Bechinger B (2010) NMR structures of the histidine-rich peptide LAH4 in micellar environments: membrane insertion, $\mathrm{pH}$-dependent mode of antimicrobial action, and DNA transfection. Biophys J 99(8):2507-2515. https://doi. org/10.1016/j.bpj.2010.05.038

20. Zhang TT, Kang TH, Ma B, Xu Y, Hung CF, Wu TC (2012) LAH4 enhances CD8+ T cell immunity of protein/peptide-based vaccines. Vaccine 30(4):784-793. https://doi.org/10. $1016 /$ j.vaccine 2011.11 .056

21. Moulay G, Leborgne C, Mason AJ, Aisenbrey C, Kichler A, Bechinger B (2017) Histidine-rich designer peptides of the LAH4 family promote cell delivery of a multitude of cargo. J Pept Sci 23(4):320-328. https://doi. org/10.1002/psc.2955

22. Liu Y, Kim YJ, Ji M, Fang J, Siriwon N, Zhang LI, Wang P (2014) Enhancing gene delivery of adeno-associated viruses by cell-permeable peptides. Mol Ther Methods Clin Dev 1:12. https://doi.org/10.1038/mtm.2013.12

23. Fenard D, Genries S, Scherman D, Galy A, Martin S, Kichler A (2013) Infectivity enhancement of different HIV-1-based lentiviral pseudotypes in presence of the cationic amphipathic peptide LAH4-Ll. J Virol Methods 189 (2):375-378. https://doi.org/10.1016/j. jviromet.2013.02.005

24. Fenard D, Ingrao D, Seye A, Buisset J, Genries S, Martin S, Kichler A, Galy A (2013) Vectofusin-1, a new viral entry enhancer, strongly promotes lentiviral transduction of human hematopoietic stem cells. Mol Ther Nucleic Acids 2:e90. https://doi.org/10. $1038 / \mathrm{mtna} .2013 .17$

25. Majdoul S, Seye AK, Kichler A, Holic N, Galy A, Bechinger B, Fenard D (2016) Molecular determinants of vectofusin- 1 and its derivatives for the enhancement of lentivirally mediated gene transfer into hematopoietic stem/progenitor cells. J Biol Chem 291 (5):2161-2169. https://doi.org/10.1074/ jbc.M115.675033

26. Gemmill KB, Muttenthaler M, Delehanty JB, Stewart MH, Susumu K, Dawson PE, Medintz IL (2013) Evaluation of diverse peptidyl motifs for cellular delivery of semiconductor quantum dots. Anal Bioanal Chem 405(19):6145-6154. https://doi.org/10.1007/s00216-013-69822

27. Abbate V, Liang W, Patel J, Lan Y, Capriotti L, Iacobucci V, Bui TT, Chaudhuri P, Kudsiova L, Vermeer LS, Chan PF, Kong X, Drake AF, Lam JK, Bansal SS, Mason AJ (2013) Manipulating the $\mathrm{pH}$ response of 2,3-diaminopropionic acid rich peptides to mediate highly effective gene silencing with low-toxicity. J Control Release 172(3):929-938. https://doi.org/10.1016/j. jconrel.2013.09.033

28. Caplen NJ, Parrish S, Imani F, Fire A, Morgan RA (2001) Specific inhibition of gene expression by small double-stranded RNAs in invertebrate and vertebrate systems. Proc Natl Acad Sci U S A 98(17):9742-9747. https://doi. org/10.1073/pnas.171251798

29. Aisenbrey C, Bechinger B, Grobner G (2008) Macromolecular crowding at membrane interfaces: adsorption and alignment of membrane peptides. J Mol Biol 375(2):376-385. https:// doi.org/10.1016/j.jmb.2007.10.053

30. Marquette A, Mason AJ, Bechinger B (2008) Aggregation and membrane permeabilizing properties of designed histidine-containing cationic linear peptide antibiotics. J Pept Sci 14(4):488-495. https://doi.org/10.1002/ psc. 966 
31. Harzer U, Bechinger B (2000) Alignment of lysine-anchored membrane peptides under conditions of hydrophobic mismatch: a CD, $15 \mathrm{~N}$ and $31 \mathrm{P}$ solid-state NMR spectroscopy investigation. Biochemistry (43):13106-13114

32. Andrushchenko VV, Vogel HJ, Prenner EJ (2007) Optimization of the hydrochloric acid concentration used for trifluoroacetate removal from synthetic peptides. J Pept Sci 13 (1):37-43. https://doi.org/10.1002/psc.793

33. Boussif O, Zanta MA, Behr JP (1996) Optimized galenics improve in vitro gene transfer with cationic molecules up to 1000-fold. Gene Ther 3(12):1074-1080 